\title{
Tungsten Karbür Besleme Stoğundan Elde Edilen Parçalar İçin İdeal Çözücünün Araştırılması
}

\author{
Kamran SAMET ${ }^{1}$, Mehmet SUBAŞI ${ }^{2 *}$, Çetin KARATAŞ ${ }^{1}$ \\ ${ }^{I}$ Gazi Üniversitesi, Teknoloji Fakültesi, İmalat Mühendisliği Bölümü, Ankara \\ ${ }^{2}$ Gazi Üniversitesi, Teknik Bilimler Meslek Yüksek Okulu, Makine ve Metal Teknolojileri Bölümü, Ankara \\ (ORCID: 0000-0002-4159-3610) (ORCID: 0000-0003-4826-9175) (ORCID: 0000-0003-0005-3068)
}

\section{$\ddot{O} \mathbf{z}$}

Bu çalışmada tungsten karbür- kobalt (WC-Co) besleme stoğundan Toz Enjeksiyon Kalıplama (TEK) yöntemi ile elde edilmiş numunelerin kimyasal bağlayıcı aşamasında kullanılacak çözücü türü araştırılmıştır. TEK yöntemi ile WC-Co besleme stoğundan hazırlanan deney numunelerinin kimyasal bağlayıcı giderme deneyleri onüç farklı çözücü (Toluen, Benzen, Heptan, Aseton, Etanol, Karbon tetraklorür $\left(\mathrm{CCl}_{4}\right)$, Etanol+ Karbon tetraklorür $\left(\mathrm{CCl}_{4}\right)$, Metanol, Nitrik asit, Hidroklorik asit, Sülfürik asit, Kloroform, Dikloroetan) kullanılarak gerçekleştirilmiştir. Deneyler sonucunda WC-Co besleme stoğu için bulunabilirlik ve maliyet açısından en ideal çözücünün etanol olduğu belirlenmiştir. Ayrıca deneyler sonucunda $60{ }^{\circ} \mathrm{C}$ sıcaklık ve 60 saat sürede etanol içerisinde tutulan parçalarda hedeflenen sonuçların elde edildiği belirlenmiştir.

Anahtar kelimeler: Bağlayıcı Giderme, Toz Enjeksiyon Kalıplama, Tungusten Karbür, Çözücü

\section{Investigation of The Ideal Solvent For Parts Obtained From Tungsten Carbide Feedstock}

\begin{abstract}
In this study, the solvent type used in the chemical debinding process of the samples manufactured from tungsten carbide - cobalt (WC-Co) feedstock by Powder Injection Molding (PIM) method was investigated. Chemical debinding process experiments of the test samples prepared from WC-Co feedstock by PIM method were carried out using thirteen different solvents (Toluene, Benzene, Heptane, Acetone, Ethanol, Carbon tetrachloride $\left(\mathrm{CCl}_{4}\right)$, Ethanol + Carbon tetrachloride $\left(\mathrm{CCl}_{4}\right)$, Methanol, Nitric acid, Hydrochloric acid, Sulfuric acid, Chloroform Dichloroethane). As a result of the experiments, ethanol was determined to be the most ideal solvent for WC-Co feedstock in terms of availability and cost. In addition, as a result of the experiments, it was determined that the targeted results were obtained in parts kept in ethanol at $60{ }^{\circ} \mathrm{C}$ temperature for 60 hours.
\end{abstract}

Keywords: Debinding, Powder Injection Molding, Tungsten Carbide, Solvent

\section{Giriş}

TEK yöntemi toz ve bağlayıcı sistemin karıștırılması ile besleme stoğunun hazırlanması, besleme stoğunun kalıplanması, bağlayıcı giderme ve sinterleme olmak üzere dört temel aşamadan meydana gelmektedir. TEK yönteminde bağlayıcı giderme, temel sıkıntıların kaynağı ve genellikle en fazla zaman alan aşamadır $[1,2]$.

Genel olarak besleme stoğu içerisindeki bağlayıcılar parçanın hacimce \%40'ını oluştururlar. Besleme stoğu içerisinden bütün bağlayıcıların birden uzaklaştırılması tozların dökülmesine ve böylece parçanın bozulmasına yol açar. Besleme stoğu içerisindeki bağlayıcıyı sinterleme işleminden önce çıkarmaktaki başarısızlık parçanın bozulmasıyla sonuçlanır. Bu sebeplerden dolayı literatürde bağlayıcı giderme aşamasının kimyasal ve ısıl olmak üzere iki temel aşamada yapılması gerektiği belirtilmektedir $[1,3,4]$.

\footnotetext{
*Sorumlu yazar: msubasi@gazi.edu.tr

Geliş Tarihi: 10.05.2021, Kabul Tarihi: 12.08.2021
} 
Literatürde besleme stoğu içerisinde kullanılan bağlayıcı eleman türlerine göre çok farklı çözücülerin kullanıldığı tespit edilmiştir. Baojun ve arkadaşları [5] çok elemanlı bağlayıcı sisteme sahip hacimce \% 65 toz yüklemeli WC besleme stoğunun kimyasal bağlayıcı giderme deneylerini heptan içerisinde gerçekleştirmişlerdir. Deneyler sonucunda kusursuz parça üretebilmişlerdir. Lee ve arkadaşları [6] TEK yöntemi ile MWNT/PMMA nanokompozit parça üretiminde hedefledikleri sonuçlara kimyasal bağlayıcı giderme aşamasında aseton kullanarak ulaştıklarını belirtmişlerdir. Heng ve arkadaşları [7] WC-10\%Co besleme stoğundan mikro enjeksiyon yöntemi ile parça üretimini araştırmışlardır. Araştırmaları sonucunda numunelerin bağlayıcı giderme aşamasında çözücü olarak heptan kullanımının olumlu sonuçlar verdiğini belirlemişlerdir. Li ve arkadaşları [8] WC-Co besleme stoğundan çift katmanlı parça üretimini araştırmışlardır. Kimyasal bağlayıcı giderme deneyleri aşamasında çözücü olarak trikloretan (trichloroethane) kullanmışlardır. Deney numunelerini trikloretan içerisinde 10 saatten fazla tutarak hedefledikleri sonuçları elde ettiklerini belirtmişlerdir.

Bu çalışmada WC-Co besleme stoğu için ideal çözücünün tespit edilmesine yönelik deneyler yapılmıştır. Kimyasal bağlayıcı giderme deneylerinde Toluen, Benzen, Heptan, Aseton, Etanol, Karbon tetraklorür $\left(\mathrm{CCl}_{4}\right)$, Etanol+ Karbon tetraklorür $\left(\mathrm{CCl}_{4}\right)$, Metanol, Nitrik asit, Hidroklorik asit, Sülfürik asit, Kloroform Dikloroetan olmak üzere onüç farklı çözücü kullanılmıştır. Deneyler sonucunda WCCo besleme stoğu için ideal çözücü ve bu çözücünün bağlayıcı giderme şartları araştırılmıştır.

\section{Materyal ve Metot}

Tungsten karbür - kobalt (WC-Co) besleme stoğu, Amerikan RYER firmasından, ticari bir ürün olarak temin edilmiştir. Besleme stoğuna ait spektral analiz değerleri Tablo 1'de, teknik özellikleri ise Tablo 2'de verilmiştir. Çalışmada kullanılan besleme stoğunun granül görüntüsü Şekil 1'de verilmiştir.

Tablo 1. WC-Co besleme stoğunun kimyasal bileşimi

\begin{tabular}{|l|l|l|l|l|l|l|l|l|}
\hline Elementler & $\mathrm{C}$ & $\mathrm{Cr}$ & $\mathrm{Fe}$ & $\mathrm{Mo}$ & $\mathrm{Ni}$ & $\mathrm{W}$ & Co & $\mathrm{O}$ \\
\hline Kütlece (\%) & 5,54 & 0,01 & 0,01 & 0,01 & 0,01 & 85,43 & 8,94 & 0,05 \\
\hline
\end{tabular}

Tablo 2. WC-Co besleme stoğunun teknik özellikleri

\begin{tabular}{|c|c|c|c|c|}
\hline \multirow{2}{*}{ Toz şekli } & Yoğunluk & \multicolumn{4}{|c|}{ Toz boyutu $(\mu \mathrm{m})$} \\
\cline { 3 - 5 } & & $\mathrm{D}_{10}$ & $\mathrm{D}_{50}$ & $\mathrm{D}_{90}$ \\
\hline $\begin{array}{c}\text { Karmaşık } \\
\text { şekilli }\end{array}$ & $8,0600 \mathrm{~g} / \mathrm{cm}^{3}$ & 0,15 & 0,28 & 0,52 \\
\hline
\end{tabular}

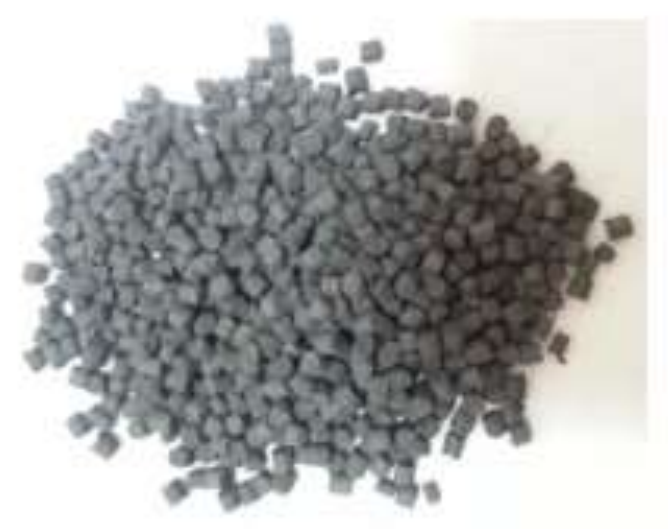

Şekil 1. WC-Co besleme stoğu

Çalışmada deney numuneleri TEK yöntemi kullanılarak hazırlanmıştır (Şekil 2). TEK numune hazırlama parametreleri Tablo 3'te verilmiştir. 


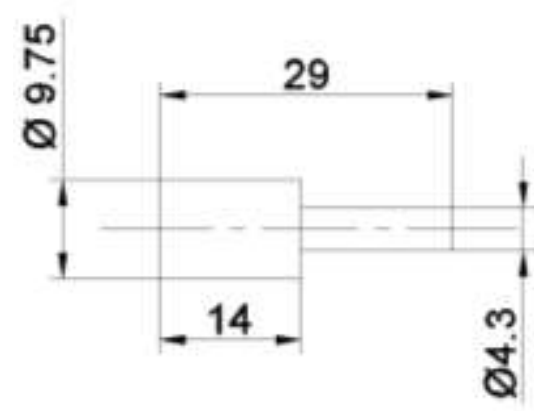

Şekil 2. WC numune ölçüleri

Tablo 3. TEK parametreleri

\begin{tabular}{|l|l|}
\hline Enjeksiyon hız1 $(\mathrm{cm} 3 / \mathrm{s})$ & 15 \\
\hline Enjeksiyon basınc1 (bar) & 120 \\
\hline Enjeksiyon süresi (s) & 2 \\
\hline Ütüleme basınc1 (bar) & 80 \\
\hline Enjeksiyon sıcaklı̆̆ $\left({ }^{\circ} \mathrm{C}\right)$ & 200 \\
\hline Kalıp sıcaklığ $\left({ }^{\circ} \mathrm{C}\right)$ & 45 \\
\hline Soğuma süresi $(\mathrm{s})$ & 5 \\
\hline
\end{tabular}

Bağlayıcı giderme deneylerinde kullanılan çözücü türleri Tablo 4'te verilmiştir. Çözücü türünü belirlemek için yapılan kimyasal bağlayıcı giderme deneyleri 24 saat sürede ve $60{ }^{\circ} \mathrm{C}$ sıcaklıkta yapılmıştır.

Tablo 4. Kimyasal bağlayıcı giderme deneylerinde kullanılan çözücüler

\begin{tabular}{|c|c|}
\hline Kimyasal & Kaynak \\
\hline Toulen & {$[9]$} \\
\hline Benzen & {$[10]$} \\
\hline Heptan & {$[5,7]$} \\
\hline Aseton & {$[6]$} \\
\hline Etanol & {$[11]$} \\
\hline Karbon tetra klorür & {$[12]$} \\
\hline Etanol+ Karbon tetra klorür & {$[12]$} \\
\hline Metanol & {$[13]$} \\
\hline Nitrik asit & {$[14]$} \\
\hline Hidroklorik asit & {$[11]$} \\
\hline Sülfürik asit & {$[14]$} \\
\hline Kloroform & {$[9]$} \\
\hline Dikloroetan & {$[15]$} \\
\hline
\end{tabular}

\section{Bulgular ve Tartışma}

Kimyasal bağlayıcı giderme aşamasında kullanılacak kimyasal çözücünün belirlenebilmesi için ilk olarak WC numuneler TEK yöntemi ile hazırlanmıștır (Şekil 3). Numunelerin hazırlandığı WC besleme stoğu ticari bir ürün olarak hazır satın alınmıştır. Besleme stoğunun temin edildiği firma kimyasal bağlayıcı giderme aşamasında hidrofloroklorokarbon esaslı AK-225 kodlu bir kimyasal önermiştir. Fakat firmanın önerdiği kimyasal ozon tabakasına zarar verdiği için Türkiye'de kullanımı yasaklanmıştır. Bundan dolayı WC besleme stoklarının kimyasal bağlayıcı giderme aşamasında kullanılan çözücüler araştııılmıştır. Literatür çalışması sonucunda deneylerin Tablo 4 de belirtilen kimyasallar ile yapılmasına karar verilmiştir. 


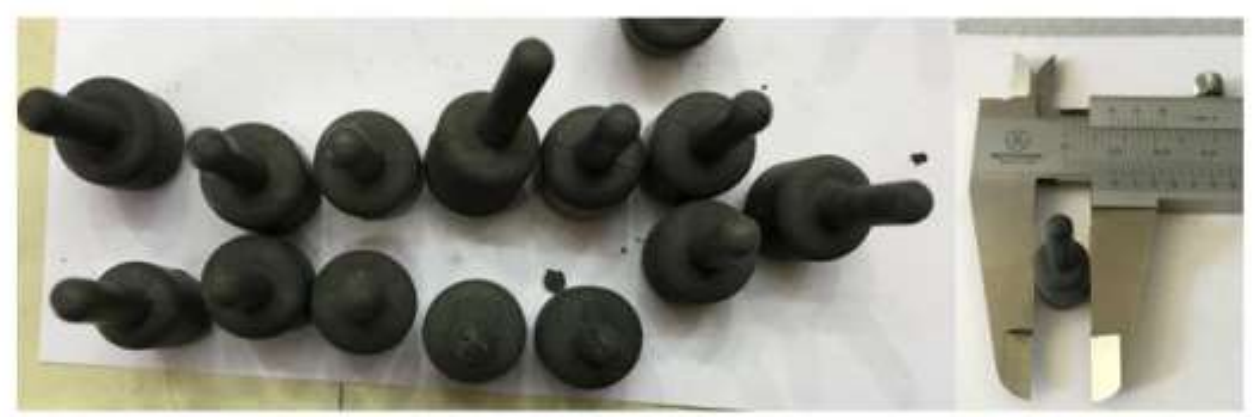

Şekil 3. WC deney numuneleri

Deneylerde kullanılan WC besleme stoğnun içerisinde ağırlıkça \%3,05 bağlayıcı bulunmaktadır. TEK yöntemi ile parça üretiminde bir aşama olan bağlayıcı giderme aşamasında \%60\%70 oranında bağlayıcının yapıdan uzaklaştırılması gerekmektedir [1]. Çalışmada yapılan deneyler sonucunda elde edilen sonuçlar Tablo 5'te verilmiştir.

Tablo 5. Kimyasal bağlayıcı giderme deney sonuçları

\begin{tabular}{|l|l|}
\hline Kullanılan kimyasal & Kütle kaybi (\%) \\
\hline Toluen & 3,24 \\
\hline Benzen & 3,2 \\
\hline Heptan & 3,63 \\
\hline Aseton & Kütle kaybı olmadı 1 \\
\hline Etanol & 2,04 \\
\hline Karbon tetraklorür (CCl4) & 3,4 \\
\hline Etanol+ Karbon tetraklorür (CC14) & 7,7 \\
\hline Metanol & Kütle kaybı olmad1 \\
\hline Nitrik asit & Numune parçaland1. \\
\hline Hidroklorik asit & Numune parçaland1. \\
\hline Sülfürik asit & Numune parçaland.. \\
\hline Kloroform & 2,02 \\
\hline Dikloroetan & 1,1 \\
\hline
\end{tabular}

Deneyler sonucunda ağırlık kayıplarının fazla olduğu numunelerde, bağlayıcı giderme işlemi sonrası numunelerde dağılma ve parçalanma gerçekleşmiştir (Şekil 4).
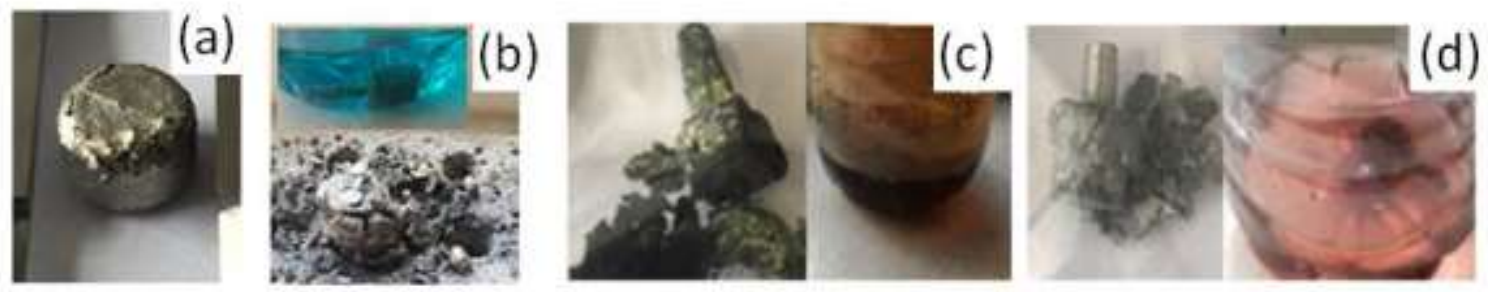

Şekil 4. Kimyasal bağlayıcı giderme deneyleri sonrası numuneler

(a) Karbon tetraklorür (b) Hidroklorik asit (c) Nitrik asit (d) Sülfürik asit

Tablo 3'deki sonuçlara göre kalıplanmış numuneden \% 60-70 oranında bağlayıcı uzaklaşmasını sağlayan çözücüler; etanol ve kloroformdur. Deneyler sonucunda bulunabilirlik ve maliyet açısından kimyasal bağlayıcı giderme aşamasında çözücü sıvı olarak etanol seçilmesinin uygun olduğu sonucuna varılmıştır.

Çözücü türünün etanol olarak belirlenmesinin ardından bağlayıcı giderme sürenin tespiti için deneyler gerçekleştirilmiştir. Hazırlanan numuneler $24,36,48,60$ ve 72 saat sürede ve $60{ }^{\circ} \mathrm{C}$ derece sıcaklıkta etanol içerisinde bekletilmiştir. Kimyasal bağlayıcı giderme deneyleri sonucunda numuneler 1 saat oda sıcaklığında kurutulmuş ve kütleleri ölçülmüştür. Ölçülen bu değerler, bağlayıcı giderme 
deneyi öncesindeki kütle değerleri ile karşılaştırılmış ve numunelerde meydana gelen ağırlık kayıpları yüzdesel olarak Şekil 5'te verilmiştir.

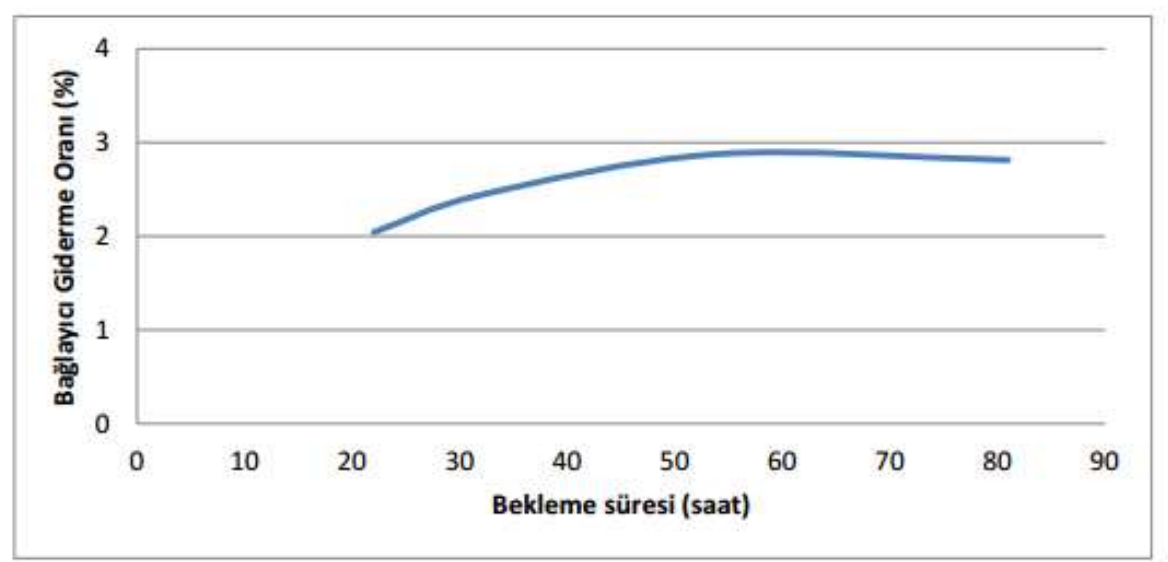

Şekil 5. Kimyasal bağlayıcı giderme süresine bağlı bağlayıcı giderme oranı

Deneyler sonucunda, bağlayıcı giderme oranı 60 saate kadar artış göstermiştir. Sonrasında bekleme süresi artmasına karşın önemli bir kütle kaybı gerçekleşmediği tespit edilmiştir. Bu sebeple bağlayıcı giderme yüzdesinin yatay seyire geçtiği 60 saatlik bekleme süresi bağlayıcı giderme süresi olarak belirlenmiştir.

Baojun ve arkadaşları [5] hacimce \% 65 toz yüklemeli WC besleme stoğundan hazırladıkları numunelerin kimyasal bağlayıcı giderme deneylerini heptan içerisinde oda sıcaklığında 5 saat bekleterek gerçekleştirmişlerdir. Bu çalışmada ise heptan ile gerçekleştirilen bağlayıcı giderme deneylerinde etanole göre daha fazla kütle kaybı olmuştur. Bu sonuca besleme stokları içerisindeki bağlayıcı bileşenlerinin farklı olmasının sebep olduğu düşünülmektedir.

Lee ve arkadaşları [6] WNT/PMMA nano kompozit numune üretiminin bağlayıcı giderme aşamasında pozitif sonuçları aseton ile elde edilebileceğini belirtmişlerdir. Lee ve arkadaşları ürettikleri parçalardan bağlayıcı sistemin uzaklaştırılmasının genel yaklaşımlardan farklı ve zor olduğunu belirtmişlerdir. İki çalışma arasındaki farklılığa numunelerin hazırlandığı besleme stoğu ve bağlayıcı reçetelerinin sebep olduğu sonucuna varılmıştır.

Heng ve arkadaşları [7] WC-10\%Co besleme stoğundan mikro enjeksiyon yöntemi ile parça üretimini araştırmışlardır. Parçaların hazırlandığı besleme stoğu parafin, polietilen, oleik asid ve stearik asit olmak üzere dört bileşenden meydana getirilmiştir. Heptan içerisinde $80^{\circ} \mathrm{C}$ de 20 dakika süresince bağlayıcı giderme deneyleri yapmışlar ve kusursuz parça üretebilmişlerdir. Bu çalışmada ise belirlenen bağlayıcı giderme süresi çok daha uzundur (60 saat). Bunun sebebi deneylerde kullanılan numunelerin hacim değerleri arasındaki farktır. Heng ve arkadaşları çalışmalarında ideal sonuçları heptanda elde etmelerine rağmen bu çalışmada ideal sonuçlar etanolde elde edilmiştir. Bunun sebebi olarak da çalışmalarda kullanılan besleme stoklarının içerisindeki bağlayıcı sistem elemanlarının farklılı̆̆ının sebep olduğu düşünülmektedir.

Li ve arkadaşları [8] WC-Co besleme stoğundan çift katmanlı parça üretiminin kimyasal bağlayıcı giderme aşamasında 10 saat ten daha fazla trikloretan içerisinde tutarak kusursuz parça üretilebileceğini belirtmişlerdir. Bu çalışmada ise kusursuz parça üretimi için kimyasal bağlayıcı giderme aşamasında etanolün kullanılması gerektiği sonucu belirlenmiştir. Li ve arkadaşlarının kullandıkları besleme stoğunun ve parçaların çift katmanlı olmasının bu farklılığa sebep olduğu sonucuna varılmıştır.

60 saat etanol içerisinde yapılan kimyasal bağlayıcı giderme deneyleri sonrası numuneler 1 saat oda sıcaklığında kurutulmuştur. Kurutma işlemi sonrası numunelerin mikroyapıları incelenmiștir. Şekil 6'te bağlayıcı giderme işlemi öncesi ve sonrası numunelerin SEM görüntüleri verilmiştir. Şekil 6a'da bağlayıcı giderme işlemi öncesinde jelsi bir yapının (bağlayıcıların) tozları sardığı ve homojen bir yapı oluşturduğu, Şekil 6b'de ise bağlayıcı giderme işleminden sonra bu yapının ortamdan kaybolduğu/azaldığı belirlenmiştir. 

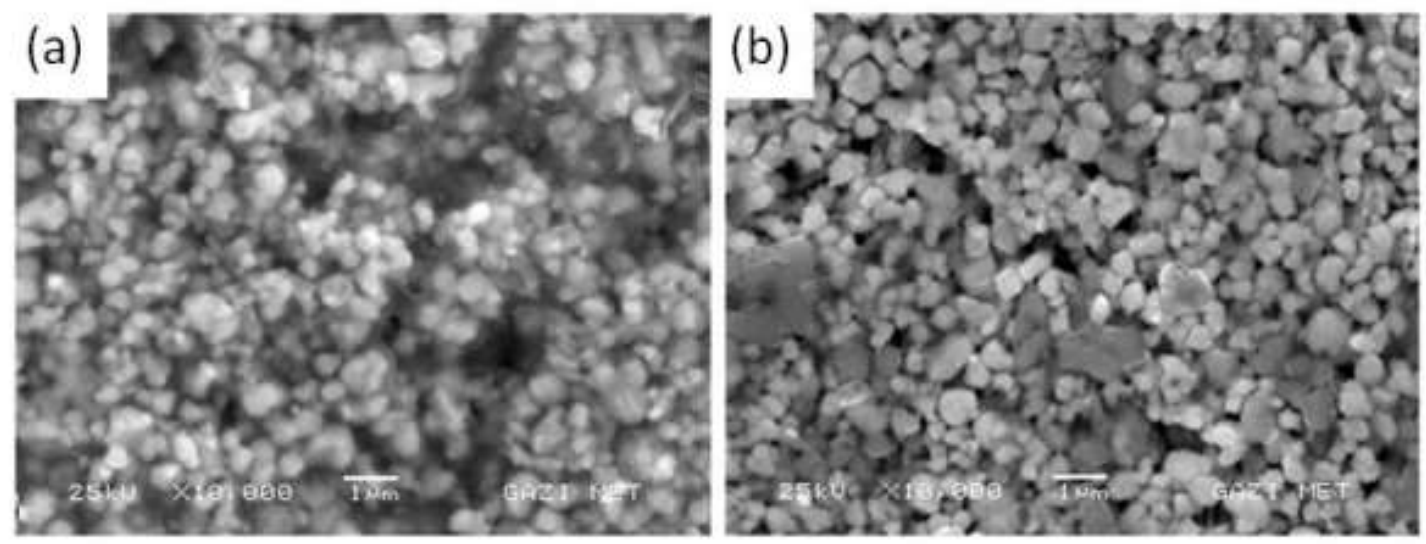

Şekil 6. TEK yöntemi ile hazırlanan parçaların kimyasal bağlayıcı giderme işlemi (a) öncesi (b) sonrası SEM görüntüsü

$\mathrm{Bu}$ görüntüler literatür çalışmaları ile karşılaştırıldığında benzer sonuçlar elde edildiği görülmüştür. Çalışmalarda bağlayıcı giderme işleminden sonra numunelerin mikroyapısı incelendiğinde tozların net bir şekilde seçilebildiği gözlemlenmiş̧ir [16,17].

\section{Sonuç ve Öneriler}

TEK yöntemi ile WC-Co besleme stoğundan kusursuz parça üretebilmek için bağlayıcı giderme aşamasında kullanılacak çözücünün belirlenmesi için deneyler yapılmıştır. Deneylerde onüç farklı çözücü (Toluen, Benzen, Heptan, Aseton, Etanol, Karbon tetraklorür $\left(\mathrm{CCl}_{4}\right)$, Etanol+ Karbon tetraklorür $\left(\mathrm{CCl}_{4}\right)$, Metanol, Nitrik asit, Hidroklorik asit, Sülfürik asit, Kloroform Dikloroetan) kullanılmıştır. Çalışma sonucunda elde edilen sonuçlar şunlardır;

- WC-Co besleme stoğu için ideal çözücü etanol dür.

- Nitrik asit, Hidroklorik asit, Sülfürik asit çözücülerinde numuneler parçalanmıştır.

- Aseton ve Metanol çözücülerinde kütle kaybı olmamıştır.

- Toluen, Benzen, Heptan, Karbon tetraklorür $\left(\mathrm{CCl}_{4}\right)$, Etanol+ Karbon tetraklorür $\left(\mathrm{CCl}_{4}\right)$ çözücülerinde kütle kaybı çok fazla olmuştur bunun sonucunda numuneler dağılmıştır.

- Etanol ile yapılacak kimyasal bağlayıcı giderme aşamasında 60 saate kadar bağlayıcı giderme oranında artı̧̧ olmuştur.

- WC-Co besleme stoğu için etanol ile yapılacak ideal kimyasal bağlayıcı giderme süresi 60 saattir.

\section{Teșekkür}

Bu çalışamanın ortaya çıamasındaki desteklerinden dolayı TÜBİTAK (Proje No. 115M437) ve Gazi Üniversitesi'ne (Proje No. 07 / 2016-21) teşekkürlerimizi sunarı.

\section{Yazarların Katkısı}

Çalışmaya tüm yazarlar eşit oranda katkı sunmuştur.

\section{Çıkar Çatışması Beyanı}

Yazarlar arasında herhangi bir çıkar çatışması bulunmamaktadır.

\section{Araştırma ve Yayın Etiği Beyanı}

Yapılan çalışmada araştırma ve yayın etiğine uyulmuştur. 


\section{Kaynaklar}

[1] German R.M. 1990. Powder injection molding. Cambridge Univ Press, 1-457.

[2] Palacı Y. 1994. Kapileri emme mekanizması ile enjeksiyonda kalıplanmış parçadan bağlayıcının alınması, Yüksek Lisans Tezi, İstanbul Teknik Üniversitesi, İTÜ Fen Bilimleri Enstitüsü, İstanbul.

[3] Subaşı M., Safarian A., Karataş Ç. 2019. The investigation of production parameters of Ti-6Al$4 \mathrm{~V}$ component by powder injection molding. The International Journal of Advanced Manufacturing Technology, 105:4747-4760.

[4] Urtekin L, Genç A, Bozkurt F. 2019. Fabrication and simulation of feedstock for titaniumpowder injection-molding cortical-bone screws. Mater Tehnol, 53: 619-25.

[5] Baojun Z., Xuanhui Q. and Ying T. 2002. Powder injection molding of WC-8\% Co tungsten cemented carbide. International Journal of Refractory Metals and Hard Materials, 20(5-6): 389-394.

[6] Lee W.-J., Lee S.-E. and Kim C.-G. 2006. The mechanical properties of MWNT/PMMA nanocomposites fabricated by modified injection molding. Composite Structures, 76(4): 406-410.

[7] Heng S. Y., Norhamidi M., Sulong A. B., Abdolali F., Sri Y., Amin M. 2013. Effect of sintering temperature on the mechanicaland physical properties of $\mathrm{WC}-10 \% \mathrm{Co}$ through micropowderinjection molding (mPIM), Ceramics International. 39: 4457-4464.

[8] Li T., Qingfa L., Fuh J.Y.H., Poh C. Y., Lu L. 2009. Two-material powder injection molding of functionally graded WC-Co components, Int. Journal of Refractory Metals \& Hard Materials. 27: 95-100.

[9] Nishimura K. and Yoshino K., 1995. Binder system for use in the injection molding of sinterable powders and molding compound containing the binder system, Google Patents, 1-10.

[10] Mutsuddy B.C. and Ford R.G. 1994. Ceramic injection molding. Vol. 1. Springer Science\& Business Media, 1-152.

[11] Diaz-Cano A., Trice R.W. and Youngblood J.P. 2017. Stabilization of highly-loaded boron carbide aqueous suspensions, Ceramics International, 43 (12): 85728578 .

[12] Okumura K.-i., Chono K., Ozeki H. and Hamada T. 1991. Reaction injection molding method. Google Patents, 1-10.

[13] Chen A.T., Farrissey W.J.J. and Robert G.N.I. 1978. Polyester amides suitable for injection molding. Google Patents, 1-10.

[14] Fukushima M. and Iwanami T. 1975. Molding material. Google Patents, 1-10.

[15] Imai T., Hashimoto M. and Harima S. 2001. Polypropylene resin composition and injection-molded article thereof. Google Patents, 1-10.

[16] Qu X., Gao J., Qin M. and Lei C. 2005. Application of a wax-based binder in PIM of WC-TiC-Co cemented carbides. International Journal of Refractory Metals and Hard Materials, 23 (4-6): 273-277.

[17] Enneti R.K., Prough K.C., Wolfe T.A., Klein A., Studley N. and Trasorras J.L. 2018. Sintering of WC-12\% Co processed by binder jet 3D printing (BJ3DP) technology. International Journal of Refractory Metals and Hard Materials, 71: 28-35. 